\title{
The Experiences of Mothers Bereaved by Suicide: An Exploratory Study
}

\author{
Joan Louise Sugrue \\ Stanhope Centre, Dublin, Ireland \\ Sinead McGilloway \\ Department of Psychology, National University of Ireland at Maynooth, Maynooth, Ireland \\ Orla Keegan \\ Irish Hospice Foundation, Dublin, Ireland
}

\begin{abstract}
To ascertain the meaning of their loss, the authors explored the experiences of 7 biological mothers bereaved by suicide. Purposive sampling was used and 1-to-1 interviews were conducted and analyzed using Interpretative Phenomenological Analysis. Four themes emerged: (a) silencing grief; (b) shattered assumptions; (c) constructing a narrative; and (d) the depth of a mother's grief. Mothers experienced intense prolonged grief with many psychological and physical symptoms; one acknowledged strong suicidal thoughts and one had attempted suicide. The findings suggest a need for care professionals to be aware of, and to target, this vulnerable subgroup.
\end{abstract}

Little is known about the impact of suicide on the "survivors" or the suicide-bereaved, and the concept of a mother's grief following the suicide of her child remains poorly understood. The mother-child bond is often one of the strongest (Farnsworth \& Allen, 1996) and the death of a child creates profound changes in a mother's life (Thrift \& Coyle, 2005). Little research has examined the impact on mothers of losing a child; most studies have focused on both parents. Arguably however, the experiences of mothers and fathers may be very different. For example, mothers tend to express more intense grief than fathers (Saarinen, Jukka, Viinamaki, Lehtonen, \& Lonnqvist, 2000), as well as excessive guilt for failing to prevent the death (Farnsworth \& Allen, 1996). Furthermore, researchers have given little attention to mothers' own accounts of their experiences, despite the general consensus within the literature that the death of a child is the most traumatic loss that can be encountered (Stroebe \& Schut, 2001).

Received 21 October 2011; accepted 18 September 2012.

Address correspondence to Joan Louise Sugrue, Stanhope Centre, Lower Grangrgorman, Dublin 7, Ireland. E-mail: joan.sugrue@hse.ie
Those bereaved by suicide have also been shown to be a high-risk group for suicide (Krysinska, 2003). Arguably therefore, mothers bereaved by suicide constitute a highly vulnerable group in need of appropriate care and support. For example, de Groot, Keijser, and Neeleman (2006) found that levels of felt need for professional help amongst those bereaved by suicide was nine times higher than for those bereaved through other causes. Dyregrov (2011) concluded from her review that the suicide bereaved experience a discrepancy between their needs for help and how these are met, whilst they also express a preference for outreach support; depression and a lack of information were also identified as important barriers to seeking professional help. The aim of this study was to explore the bereavement experience of mothers following their child's death by suicide.

\section{METHOD}

\section{Participants}

Four participants were in their $50 \mathrm{~s}$, two in their $60 \mathrm{~s}$, and one in her $70 \mathrm{~s}$. All lived in urban settings and were 
the biological mothers of children who had died by suicide (six sons and one daughter, aged between 16 and 44 years at the time of death). All had at least one other child. The mean length of time since the death of their child was 3.2 years. Five of the suicide victims died by hanging or strangulation; two from an overdose or overdose plus suffocation. Purposive sampling was used to recruit a sample of biological mothers who had been bereaved by their child's suicide during the previous 2 to 5 years. This period was considered sufficiently long to allow them time to process and gain perspective on their loss. Participants were recruited through a national suicide-bereaved support organisation. Eight people were identified as eligible for inclusion, 7 of whom agreed to be interviewed. A sample size of 5 to 12 was considered appropriate for purposes of interpretative phenomenological analysis (Smith \& Osborn, 2003).

\section{Materials}

A nine-item biographical questionnaire was devised to elicit sociodemographic information on participants. A semi-structured interview schedule was also developed to guide the interviews and to explore (a) reflections on motherhood and relationship; (b) immediate aftermath of suicide; (c) support and help; (d) changes in mothering and mother role; and (e) the impact and meaning of the suicide.

The interviews took place in either the participant's home or a private counseling room and appropriate support was made available following the interview. The interviews were approximately $1.5 \mathrm{hr}$ in duration and all were conducted by Joan Louise Sugrue and tape recorded with consent. Tapes were transcribed verbatim. The study was approved by the Royal College of Surgeons in Ireland Research Ethics Committee.

\section{Procedure}

The researcher (Joan Louise Sugrue) read and reread transcripts, and recorded initial thoughts and emergent themes. Themes across all transcripts were then summarized using color codes. This connecting the themes allowed the themes to be clustered together, and for each cluster a superordinate theme was produced. Repetitions of the emergent themes were assumed to be indicative of shared understandings. The analysis was iterative in that the researcher constantly checked to ensure that the interpretation was grounded in the participants' own words (Smith \& Osborn, 2003). The researcher explained codes and discussed them in a number of separate forum (with research supervisor Sinead McGilloway, professional clinical colleagues, and student peers) to aid interpretation. No conflicting interpretations emerged. A master set of superordinate themes was used as the basis for writing up the findings into a narrative, illustrated with selected quotes. Extracts that best captured the essence of participants' experiences were selected for inclusion.

\section{RESULTS}

The mothers provided detailed and rich descriptions of their experience of bereavement in the aftermath of the death of their child. Four separate but interrelated themes were identified.

\section{Silencing of My Grief}

Initially, the mothers reported that they felt compelled in some way to keep their emotion and pain hidden and to "put on a brave face." Six reported that they were afraid to release their pain and grief publicly and believed that they had to protect others from it: "I had to keep myself in check and did not want to lay my grief on them [other adult children]. I thought I was looking at a film on TV and put myself outside of this or I would have screamed" (1).

Although the funeral and burial rituals provided an opportunity for open grieving for other mourners, this was not the case for most present mothers. For example, a 50-year-old woman who had lost her son spoke about how she noticed the pain of others both at the hospital and during the funeral but was unable to acknowledge or show her own pain:

I remember the doctor asking me if I was Barry's mother and telling me she was sorry but Barry was dead and she [the doctor] was crying. I had never seen a doctor crying before. Also I was conscious of soldiers in uniform at the graveside and tears rolling down their faces. I knew soldiers in uniform were not meant to show emotions ... everyone thought I was coping as I hid it well, but I just went to rock bottom and ended up drinking and taking an overdose of tablets. (2)

Most present mothers saw the funeral as confirmation that their loved one was a special person. It was important for one mother to feel that she had validated her son's life and she wanted him to be remembered as a hero. She was determined that he would have a tumultuous send-off and that she was going to be as brave as he had been: "There is no way there was screaming and crying ... there was honour and music soared up to the sky... inside, I felt I could not bear to take another breath" (3). Another said, "you can't make a fuss. You have to do things and behave in a certain way. I thought to myself, I don't think I can survive this. It's 
the end of my life too" (4). "I asked myself "why am I not going off the rails?' But inside it was like my whole insides were pulled out. Inside I was screaming" (4).

In contrast, another mother became highly emotional at the cemetery: "I just screamed and screamed and went totally berserk when they went to lift the coffin. I threw myself on top of the coffin and was kissing it and telling him how proud of him I was" (7).

\section{Shattered Assumptions: "It's the End of the World as I Know It"}

Each of the participating mothers felt compelled to confront a situation in which the tragic loss of their child through suicide had turned their whole world upside down and shattered many of the assumptions that they previously held about themselves, their life, and their world. The experience of losing a child through suicide did not fit with their expectations of how life would unfold for them. Two mothers said, "I expected to die before my child, leaving everything organised for them ... this is a big empty void that shoves everything in [sic] perspective and makes you realise what life is all about" (7). "And I just knew the world would never be the same again. It was the end of the world as I knew it" (5).

A 67-year-old mother who had grown up within a religious family, experienced a profound loss of her faith and belief in many aspects of her life when her son died: "I don't believe in almost anything I was taught. I see life in a totally different way now. It [the world] changed utterly when he died and became a completely different place. When he died, it was just the end "(4).

Another mother spoke in a more positive way about how the death of her child led her to completely reevaluate her life and how she became less upset about things. Likewise, another reported how she had reevaluated her relationship with her remaining children and her role as a mother. She no longer believed that her children would bring their problems to her. One of the mothers used a powerful metaphor: "It was like if you look through one of those kaleidoscopes and you see a pattern and you think it is beautiful and you do not want to move it, and then it moves and it all changes and that's what happened in my life" (4).

\section{Constructing a Narrative}

Arguably, attempting to make sense of the death of a child is a major challenge for any bereaved parents (Neimeyer, 2000), yet many of the mothers in this study were able to construct a narrative that explained the death to others and to themselves. Indeed, one participant was, to some extent, prepared for the death of her child because he had previously attempted to take his own life: "One night I opened the door and he was standing there all dripping wet. He had gone into the sea and tried to drown himself" (3). However, the other women had no such expectations but could identify reasons retrospectively as to why they may have done so: "He did this to make things easier for everyone. He has shown huge courage" (3); "In the end he was totally worn out by it all. It just sort of broke him" (4).

Mothers identified family issues such as poverty, alcoholism, violence, and past bereavement as influential factors in their child's life and consequently their death. The mother of the youngest child in the sample cited bullying as a contributory factor in his death and how her son had stopped her from openly addressing this issue because he believed it would only compound his difficulties.

A subtheme of 'love and forgiveness' was prevalent throughout each of the interviews and the mothers appeared to have a great sense of understanding of the pain their child must have felt to choose to die in this way. Ironically, for some participants, it was the legacy of pain following their child's death that had facilitated that understanding: "After he died I wanted to die myself. I finally understood the pain he must have been in" (7); "There were times after his death I just wanted to die and suddenly realised this is what he must have been feeling" (5).

The following excerpt illustrates well the level of love and forgiveness many of the mothers showed for their deceased child: "I said 'thank you' for not going outside and for not having to drag through a river looking for your body, or wait for it to be washed up at sea. He was one of the most unique people I ever met. I was privileged to be his mother" (3).

Blaming is endemic in families after a suicide (Ness \& Pffeffer, 1990) and usually involves the projecting of anger and guilt outside the immediate family members onto someone or something else. However, failure and self-blame also permeated most of the mothers' accounts: "I should have seen it coming. We should not have gone on holidays and left him" (1); "I never saw nothing [sic] I just thought he was distancing himself because he was growing older" (7); "I do feel I failed him. I was not there when he died" (4); "I don't know why the hell I didn't cop on? I should have picked up that something was wrong" (5). Several participants felt that the death impacted their role as parents to their surviving children. Some described how they were not available to their children because of their continuing pain. For instance, one mother described how she was alerted to her surviving son's pain whilst another was jolted back to the reality that she had other children who needed her support: "It was not until one of his tears fell on my cheek that I woke up to the fact that my other son was crying every night of the week" (2); 
"One of them said 'Ma what about us, you are putting all your love into him and he is dead. We are here too" (1).

The narrative of "failure as a mother" is striking in its direct contrast to that of "love and forgiveness" described earlier; the mothers had no difficulty in finding forgiveness for their children and yet appeared to struggle to forgive themselves.

\section{The Depth of a Mother's Grief: "This Leaves a Scar on the Soul Forever"}

Predictably, it would be expected that stories of unhappiness and pain would emerge within a study of this kind, but the level and depth of suffering and sorrow described by the participants was striking. The following excerpt from one interview expands upon this theme:

Total devastation. I will never come to terms with this because he was my baby. What I feel is total sadness for my child that it came to a child putting something around his neck and taking his own life. His feet was [sic] only inches from the ground and his whole body was just scrunched up. (7)

The intensity of the mother-child bond and the natural inclination for mothers to want to hold and touch their child is well established in the literature (Rando, 1986). In the current study, one of the participants described the constant longing to hold her lost child and smell his skin; for her, this was one of the most difficult feelings to manage. Similarly, another mother commented that, had her son not been cremated, she would have battled with an urge to go and "dig him up" from his grave and bring him home again.

Notably, all of the mothers indicated that they had experienced mental health problems following the suicide, including depression, nightmares and insomnia, poor concentration, and numbness or shock. Some also alluded to physical health issues such as heart problems and eating disorders. One mother described her pain as follows: "I sat looking at a wall for weeks and had to go on medication. It's a hole in my stomach that doesn't go away and it's like someone putting their hand in your body and pulling your heart out" (7).

Another mother who discovered the body of her dead son described her reaction when she found him: "I just lay beside him and tried to hold his hand but rigor mortis had set in. I did not want to tell anyone-as I did not want them to take him away from me" (3).

This seemed to be her special time to say goodbye to her son in private before his body was removed. These intense feelings of love were peppered throughout all of the transcripts and led to great agony and anguish. The strength of this mother-child bond and the intense bereavement is continued in these powerful excerpts:
"And to know your son is locked in a freezer and you want to cover him up and warm him and get him to sing our songs from when he was a baby" (2).

"I was very scared as I did not know what I would see. I did not want to go and see my only son in a coffin. I thought I would die" (5); "The very worst thing was seeing him in a coffin. I collapsed and I vomited before I went into the inquest. The fact that he was going into a furnace was so hard and knowing his beautiful eyes would be burnt to a cinder" (2).

A further constant source of anxiety for many mothers related to how their child felt and what they may have been thinking at the time of their death. The following comments illustrate the depth of their anguish: "I would get this feeling of 'Oh God' imagine how he felt. He must have been so lonely. I can't bear how unhappy and lonely he must have been" (4); "He must have thought that nobody wanted him" (5).

Importantly, many of the mothers alluded to having had strong suicidal feelings and one admitted to a suicide attempt following her son's death. The urge to want to still take care of their child, even in death, was prevalent in many of the transcripts:

"I wanted to go and find my child and know he was ok. I drove to his grave and took tablets and waited for him to come and pick me up. My partner found me and took me to hospital. I woke up two days later and finally understood the pain he must have been in." (2)

\footnotetext{
"I just wanted to die myself. The grief I have is like a tsunami at times and the draw to go to him was more than the draw to stay at times. I have not done it but have been lucky." (4)

"I know it's a terrible thing to say but I won't mind dying and I don't think I can survive this. It really is the end of my life too." (5)

"I needed to mind him and the only way I could do this was to go to him. It was like I could not let go of the umbilical cord." (2)
}

Present mothers totally rejected the commonly held belief that time heals grief. Emotive language was particularly evident as the women searched for appropriate words to describe how it felt to be told repeatedly that "time will heal," "grief is a cycle," and "you will feel better in time": "This will never heal - never go away. I will take this grief to my own grave" (7); "Time does not heal the scars that are left after a suicide. The scars of suicide are with you forever" (1); "In suicide, this nonsense about time heals is a load of ${ }^{* * * *}$. This is a scar on the soul forever and with a mother it goes beyond the grave" (2). All the mothers who had experienced the death of other family members agreed that the 
bereavement from suicide was very different in terms of the intensity of the pain and the complex mix of emotions that it brings.

\section{DISCUSSION}

The findings reported here add to the limited literature regarding the impact of, and difficulty in resolving, maternal bereavement following suicide. The results provide a rich, meaningful, and often disturbing account of the personal experiences and profound stress of maternal bereavement following suicide, whilst also giving a voice to this vulnerable and often neglected group. A supportive context was created by the researcher and an appropriate support protocol put in place which allowed the women to open up and tell their story. In a field where refusal rates are typically high (Ellenbogen \& Gratton, 2001), it is notable that in the first recruitment round, five out of a possible six mothers who were approached, agreed to be involved in the study.

Four separate, but related themes were identified that, collectively, provide a useful and poignant insight into the suffering of the participants and the impact of the suicidal death of their child on their lives. The first theme of feeling silenced in their grief was evident amongst most of the mothers and is consistent with a few studies conducted elsewhere (Maples, 2005; Seguine, Lesage \& Kiely 1995). All of the participants offered descriptive accounts of emotions such as numbness, denial and shock, which have been identified as leading to repression of grief (Cvinar, 2005). Furthermore, suicide is typically viewed as "unjustifiable, physically repulsive and an ambiguous death" (Maples, 2005) and it would appear that these kinds of negative attitudes led to either a conscious or subconscious reluctance or inability amongst the mothers to publically acknowledge their grief.

Each one of the participants also experienced a sense of having their world "turned upside down" and their assumptions about their life and their world shattered (Theme 2). Given that the shattering of assumptions in the aftermath of a traumatic event imposes a negative world view (Janoff-Bulman, 1992), it is reasonable to assume that the mothers in this study faced the arduous task of reconstructing a more positive world view in which they could feel safe again. Studies investigating assumptive world views of bereaved parents have tended to use quantitative methods (i.e., Wickie \& Marwit, 2000-2001, Matthews \& Marwit, 2003-2004) which, unlike the present study, may fall short of elucidating the full impact of the death on participants' lives. Although this study provided little evidence of hope and resilience, the findings illustrate well the mothers' fluency in the language of pain.
A further significant finding from this study was that despite the construction by mothers of positive narratives regarding their lost child, the most common narrative they constructed around themselves was one of "failure as a mother" (Theme 3). This may perhaps be best understood in the context of McGoldrick, Anderson, and Walsh's (1991) argument that a child's psychological flaws become the exclusive responsibility of the mother and can lead to mothers carrying blame. This concept is further developed by Forcey (1987) who argued that we are told by social commentators that, behind every violent, mentally ill or merely unfulfilled male, there is a mother. Therefore, although shame was absent from the findings in this study, blame and guilt were clearly not. As noted by Seguin et al. (1995), the current clinical focus on suicide prevention tends to reinforce feelings of guilt and blame in parents who fail to prevent their children from dying by suicide, although Maples (2005) claimed that certain components of suicide risk assessment (e.g., familial factors), potentially contribute to feelings that parents may have failed their children. The guilt expressed by the mothers at having outlived their offspring is also consistent with findings from Farnsworth and Allen (1996), whereas Forcey (1987) stated that the suicide of a child becomes, in the mind of the mother, the ultimate violent failure of mothering. It is not surprising, therefore, to find that "failure as a mother" was such a predominant narrative in this study.

The commonly acknowledged "depth of a mother's grief" evident in this study was identified as the final theme in this study (Theme 4); this was multilayered in terms of illustrating the extensive impact on both physical and mental health, as well as the unique intensity and duration of the grief, particularly when compared to other forms of loss. Many mothers reported physical and mental health problems, and similarly Maples (2005) found that parents may experience a wide range of health difficulties immediately after the death and in the longer term. Furthermore, there is evidence to suggest that Health Related Quality of Life is significantly worse for bereaved than nonbereaved parents up to 21 years after the death (Song et al., 2010). The lowest levels of Health Related Quality of Life were reported in cases involving a violent death, including suicide. An additional key finding in the present study was the mothers' abuse of medication and/or alcohol to help them cope; alcohol use is not incorporated in many studies as an outcome variable and it is interesting to note that this was spontaneously raised by the mothers here. Where alcohol use in bereavement has been assessed (Vance, Boyle, Najman, \& Thearle, 2002), elevated use was demonstrated amongst sudden infant death bereaved fathers but not mothers.

Most of the study participants also developed significant suicidal thoughts/ideation and indeed one mother 
had attempted suicide. This is in line with a study by Krysinska (2003) who presented interesting data to show that suicide survivors are more likely to engage in suicidal ideation than others not exposed to loss by suicide. Several researchers have also proposed explanations to better understand the mechanisms underlying increased suicide risk following the loss of a child by suicide, including identifying with the deceased and punishment for perceived self-blame (Clarke \& Goldney, 2000). The mothers in the current study put forward different reasons from those above, to account for their suicide ideation/behavior. Although they all had other children, they felt an extraordinarily strong desire to go and seek out their dead child. They wanted to know that their child was alright, even in death, and they felt the only way they could do this was to die themselves. This finding is previously unreported in the literature and it is possible that this phenomenon is unique to mothers and closely related to the mother-child bond. However, further research is needed to explore this in more detail and to ascertain the role of cultural factors and, in particular, the traditionally matriarchal society in Ireland.

With regard to the intensity and the expected duration of grieving, it was clear that the women in this study believed that their grief would never end. This is an interesting finding that is both consistent and inconsistent with the literature. Several larger studies show that these kinds of feelings tend to be more common amongst the newly bereaved who, in their first months or years after the loss, feel that they will always remain sad, but that eventually as time passes, hope reemerges for them (e.g., Murphy, Johnson, \& Lohan, 2003; Dyregrov \& Dyregrov, 2008). However, more recent qualitative research illustrated an ambivalence amongst suicide-bereaved mothers toward their own mortalityup to 10 years after the death (Harper, O'Connor, Dickinson, \& O'Carroll, 2011). To some extent, the prospect of death was viewed as the end to pain.

McIntosh and Hubbard (1998) concluded that suicide bereavement is neither unique nor unusually complicated and long lasting when compared to other types of sudden bereavement. By contrast, Ness and Pfeffer (1990), in line with the present study, argue that survivors of suicide may never resolve their feelings entirely. Safinofsky (2007), in a recent systematic review, further supported the claim that maternal bereavement is long-term, whilst Dyregrov, Nordanger, and Dyregrov (2003) identified self-isolation as the strongest predictor of psychosocial distress in suicide survivors, with guilt identified as a common reason for withdrawal from society.

Participants' grief was more persistent and intense than the grief they felt in response to other losses in their life, such as the loss of a parent or sibling. Likewise, Leahy (1992-1993) found that bereaved mothers had significantly higher levels of depression than both widows and bereaved adult daughters. Furthermore, the Leiden bereavement study identified that the kinship relationship to the deceased played a prominent role in the severity of grief, with mothers more strongly affected than other immediate family members (Cleiren, Diekstra, Kerkhof, \& van der Wal, 1994). However, a need for further research in this area is indicated.

\section{LIMITATIONS OF THE STUDY}

This study was limited by a modest sample size, albeit one that was appropriate for interpretative phenomenological analysis and sufficiently diverse in terms of age and background of participants as well as the age of the child and the background to the death. There was no comparison group (e.g., mothers bereaved for reasons other than suicide) whilst other family members were excluded, including men who tend to be underrepresented in this field. All of the participants had also identified their need for bereavement support and had contacted the bereavement support organization involved in the study. This may suggest that these mothers were more vulnerable than other suicide-bereaved mothers and were, therefore, not typical. The extent to which these mothers' experiences mirror the experiences of others should be investigated more closely, with a particular emphasis on nonservice user accounts.

\section{CONCLUSION}

This study highlighted a number of factors not previously reported in the literature, including participants' reasons for wanting to die in order to be with their child and the impact of guilt and blame on their belief of themselves as a failure as a mother. These findings highlight a need to focus on this vulnerable subgroup in future research as well as other subgroups such as fathers, siblings, and the wider family circle. It would also be interesting to establish the extent to which bereaved mothers are accessing health and social care services such as GPs, mental health, and alcohol treatment services. Another potentially fruitful line of research might involve assessing the cross-generational impact of suicide (in view of the potentially large numbers of family members affected), as well as the effects of stigma and shame (which did not emerge in the current study).

Overall, this study suggests that the needs of those bereaved by suicide should be a concern for health care providers. The total cost of the unmet needs of this group, in terms of suffering, health problems, and economic losses, are unknown and incalculable (Muller \& Thompson, 2003). This exploratory study shows that suicide-bereaved mothers deal with immense grief and 
a complexity of issues, which not only impact on their overall health and well-being, but more importantly, change their lives and the lives of their families forever.

\section{REFERENCES}

Clarke, S., \& Goldney, R. (2000). The impact of suicide on relatives and friends. In K. Hawton \& V. Heeringen (Eds.), The international handbook of suicide and attempted suicide (pp. 467-484). Chichester, UK: Wiley \& Sons.

Cleiren, M. P., Diekstra, R. F., Kerkhof, A. J., \& van der Wal, J. (1994). Mode of death and kinship in bereavement: Focusing on "who" rather than "how." Crisis, 15, 22-36.

Cvinar, J. (2005). Do suicide survivors suffer social stigma: A review of the literature. Perspectives in Psychiatric Care, 41, 14-21.

de Groot, M., Keijser, J., \& Neeleman, J. (2006). Grief shortly after suicide and natural death: A comparative study among spouses and first degree relatives. Suicide and Life-Threatening Behavior, $36,418-443$.

Dyregrov, K. (2011). What do we know about needs for help following suicide in different parts of the world? A phenomenological perspective. Crisis, 32, 310-318.

Dyregrov, K., \& Dyregrov, A. (2008). Effective grief and bereavement support: The role of family, friends, colleagues, schools, and support professionals. London, UK: Jessica Kingsley Publishers.

Dyregrov, K., Nordanger, D., \& Dyregrov, A. (2003). Predictors of psychosocial distress after suicide, SIDs and accidents. Death Studies, 27, 143-165.

Ellenbogen, E., \& Gratton, F. (2001). Do they suffer more? Reflections on research comparing suicide survivors to other survivors. Suicide and Life-Threatening Behavior, 31, 83-89.

Farnsworth, E. B., \& Allen, K. (1996). Mothers' bereavement; Experiences of marginalization, stories of change. Family Relations, $15,360-367$.

Forcey, L. R. (1987). Mothers of sons: Toward an understanding of responsibility. New York, NY: Praeger.

Harper, M., O'Connor, R., Dickinson, A., \& O'Carroll, R. (2011). Mothers' continuing bonds and ambivalence to personal mortality after the death of their child: An interpretive phenomenological analysis. Psychology, Health and Medicine, 16, 203-214.

Janoff-Bulman, R. (1992). Shattered assumptions. New York, NY: The Free Press.

Krysinska, K. (2003). Loss by suicide: A risk factor for suicidal behaviour. Journal of Psychosocial Nursing, 41(7), 34-41.

Leahy, J. M. (1992-1993). A comparison of depression in women bereaved of a spouse, child or a parent. Omega, Journal of Death and Dying, 26, 207-217.

Maples, M. (2005). Parental portraits of suicide; narrating the loss of a young adult. Unpublished PhD Thesis. University of New England, Madgwick, Australia.
Matthews, L. T., \& Marwir, S. J. (2003-2004). Examining the assumptive world views of parents bereaved by accident, murder and illness. Omega Journal of Death and Dying, 48, 115-136.

McGoldrick, M., Anderson, C. M., \& Walsh, F. (1991). Women in families and in family therapy. In M. McGoldrick, M. Anderson, \& F. Walsh (Eds.), Women in families: A framework for family therapy (pp. 3-15). New York, NY: W.W. Norton and Co.

McIntosh, J. L., \& Hubbard, R. W. (1998). Survivors of suicide curriculum. Journal of Psychosocial Nursing, 41, 34-41.

Muller, E., \& Thompson, C. (2003). The experience of grief after bereavement: A phenomenological study with implications for mental health counselling. Journal of Mental Health Counselling, $25,183-203$

Murphy, S., Johnson, L. C., \& Lohan, J. (2003). Challenging the myths about parents'; Adjustment after the sudden, violent death of a child. Journal of Nursing Scholarship, 35, 359-364.

Neimeyer, R. (2000). Searching for the meaning of meaning: Grief therapy and the process of reconstruction. Death Studies, 24, 541-588.

Ness, D., \& Pfeffer, C. (1990). Sequelae of bereavement resulting from suicide. American Journal of Psychiatry, 147, 279-285.

Rando, T. A. (1986). Parental bereavement: An exception to the general conceptualizations of mourning. In T. A. Rando (Ed.), Parental loss of a child (pp. 45-58). Champaign, IL: Research Press.

Saarinen, P., Jukka, H., Viinamaki, H., Lehtonen, J., \& Lonnqvist, J. (2000). Is it possible to adapt to the suicide of a close individual? Results of a 10 year prospective follow-up study. International Journal of Social Psychiatry, 46, 182-190.

Safinofsky, I. (2007). The aftermath of suicide: Managing survivors' bereavement. The Canadian Journal of Psychiatry, 52, 129S-136S.

Seguin, M., Lesage, A., \& Kiely, M. (1995). Parental bereavement after suicide and accident: A comparative study. Suicide and LifeThreatening Behavior, 25, 489-497.

Smith, J. A., \& Osborn, M. (2003). Interpretative phenomenological analysis. In J. A. Smith (Ed.), Qualitative psychology. A practical guide to research methods (pp. 51-79). London, UK: Sage Publications.

Song, J., Floyd, F., Mailick Setzer, M., Greenberg, J. S., \& Hong, J. (2010). Long-term effects of child death on parents' healthrelated quality of life: A dyadic analysis. Family Relations, 59, 269-282.

Stroebe, M. S., \& Schut, H. (2001). Models of coping with bereavement: A review. In M. S. Stroebe, R. O. Hansson, W. Stroebe \& $\mathrm{H}$. Schut (Eds.), Handbook of bereavement research: Consequences, coping and care (pp. 375-403). Washington, DC: American Psychological Association.

Thrift, O., \& Coyle, A. (2005). An interpretative phenomenological analysis of maternal identity following child suicide. Counselling Psychology Review, 20, 18-23.

Vance, J. C., Boyle, F. C., Najman, J. M., \& Thearle, M. J. (2002). Couple distress after sudden infant or perinatal death: A 30 month follow up. Journal of Paediatric Child Health, 38, 368-372.

Wickie, S., \& Marwit, S. (2000-2001). Assumptive world views and the grief reactions of parents of murdered children. Omega, Journal of Death and Dying, 42, 101-113. 